\section{EVOLUCION DE LA VIVIENDA EN ESTOCOLMO}

$110-5$

\section{COMO SE VIVIA EN ESTOCOLMO EN EL PASADO}

La última parte del siglo XIX es uno de los períodos en que se incrementó más rápidamente la población de Estocolmo. La población se triplicó en algo más de 40 años. La gente se trasladaba desde las provincias que no podían soportar tal crecimiento de la población. La emigración o traslado a las zonas industrializadas eran la única posibilidad para el proletariado rural que ya no podia vivir de la tierra y porque, en esa época, Suecia estába experimentando un importante desarrollo industrial en las ciudades, incluyendo a Estocolmo, con la consiguiente fuerte demanda de mano de obra.

La población rural recién llegada encontró trabajo en Estocolmo, pero encontrar un lugar para vivir se hizo cada vez más difícil. El hacinamiento era normal, con varias personas viviendo en cada apartamento. La gente vivía fuera de las casas an-
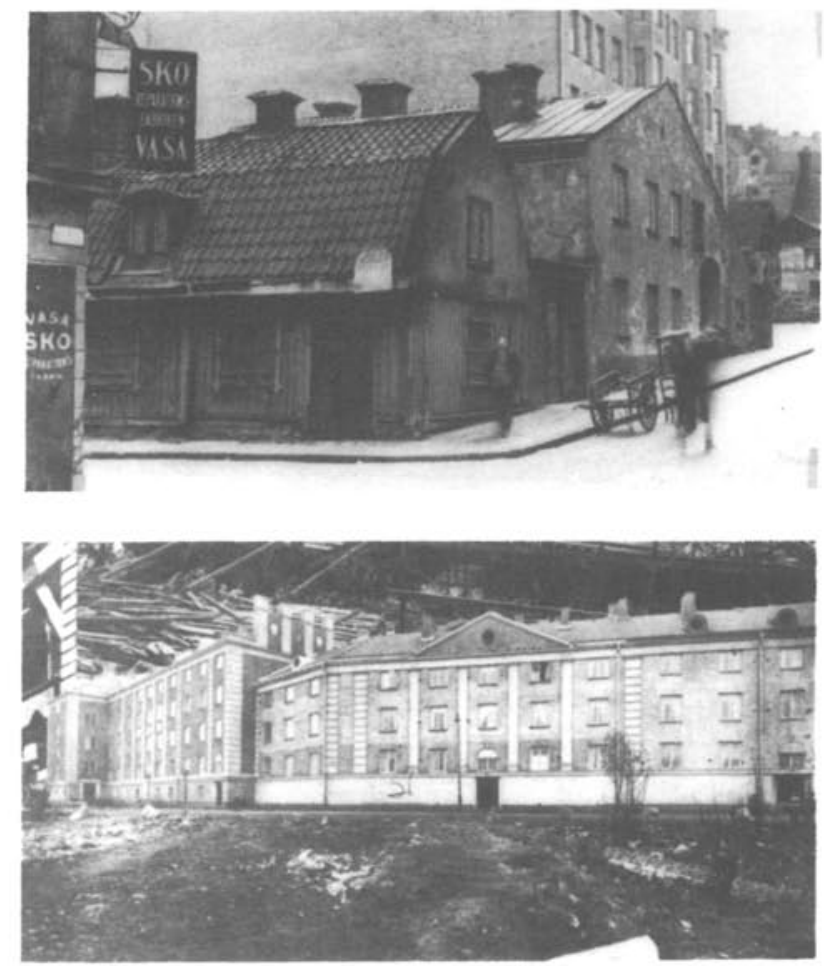

tes de que se pusiera en marcha la construcción de conjuntos residenciales, lo cual tuvo lugar con lentitud.

Hacia los primeros años de la década de 1860 , Estocolmo se hizo municipio autónomo. Una de las más importantes tareas del consejo municipal fue elaborar un plan para el desarrollo de la ciudad. Se tuvieron que prever servicios de agua, de alcantarillado y calles pavimentadas para mejorar las condiciones higiénicas. A finales de 1870 se concluyeron los planes y zonas amplias quedaron dispuestas para la construcción de viviendas. Se disponia de terreno para construir, pero gran número de viejas cabañas de madera se sustituyeron por viviendas de ladrillo, normalmente de cinco pisos, dispuestas en bloques rectangulares.

Las reglamentaciones para la construcción en las ciudades se redactaron en 1874. Junto con las ordenanzas para Estocolmo, que se promulgaron dos años después, permitieron una edificación muy compacta en los emplazamientos. Este periodo contempló la construcción de grandes casas de vecindad con muchas viviendas dando a patios pequeños, estrechos y oscuros. Los obreros y sirvientes vivian en las casas ubicadas en los patios y en pequeños apartamentos, en el ático, de las casas principales junto a la calle. El nivel de calidad era bajo, con servicios de pozo negro en los patios y solamente un grifo de agua fría y un fregadero en los apartamentos.

Para residentes más distinguidos, habia habitaciones en las plantas primera y segunda de las casas que daban a la calle. En estos apartamentos estaban instalados tocadores y servicios. Pero las diferentes clases sociales también se desplazaban y se ubicaban en distintas zonas de la ciudad. Södermalm, Kungsholmen y Vasastan se hicieron propias de la clase obrera con predominio de edificios de pequeños apartamentos.

Un habitat de mejor calidad fue concebido por arquitectos que concentraban sus esfuerzos en las fachadas. Los estilos antiguos se recogieron en la forma de ornamentación de los exteriores de las calles. Los ornamentos de estuco y de yeso se hicieron tan comunes que se producian en fábricas y se vendian por catálogo.

En esa época, las autoridades municipales no tenian ninguna influencia sobre la edificación residencial. Era el negocio de los propietarios de solares individuales y del constructor. De acuerdo con la libertad de comercio de tipo liberal introducida en 1864, cualquiera que tuviera terreno y capital a su disposición podía constituirse en constructor. 


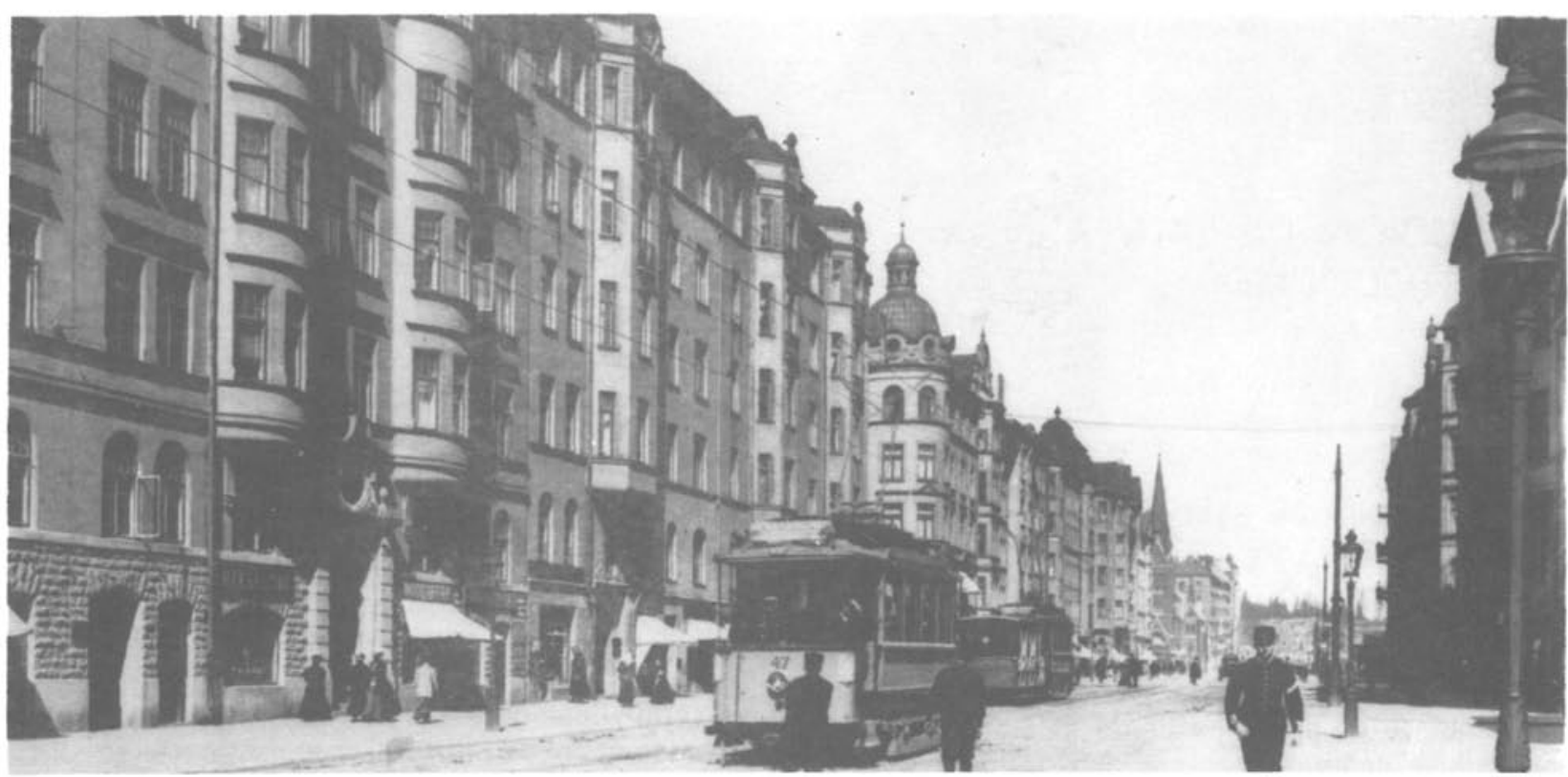

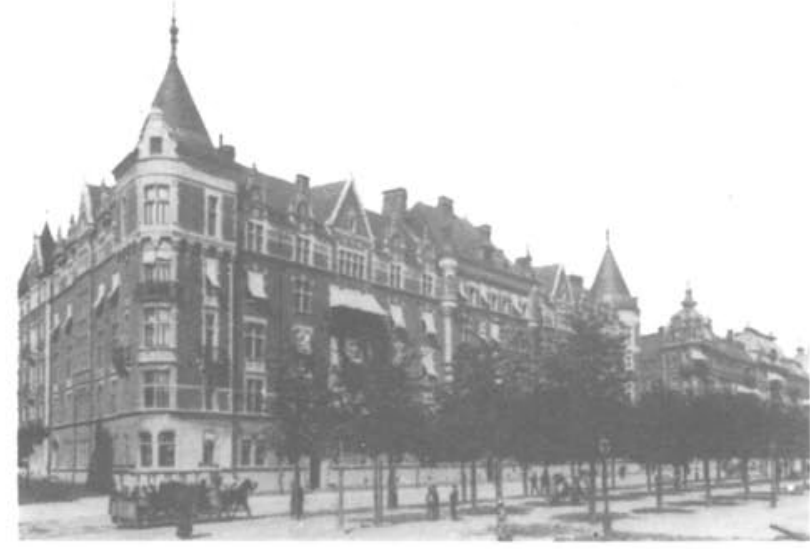

Al principio, no se exigia ningún conocimiento profesional especial. En consecuencia, muchas casas se construyeron de forma "chapucera" y deficiente desde el punto de vista técnico, con lo que se exponia a los trabajadores de la construcción a grandes riesgos. Muchos de los moradores de estas viviendas cayeron enfermos a causa de la humedad, del frio y de las corrientes de aire. El programa de renovación urbana del Municipio abarcó las pocas edificaciones que todavia se mantienen en pie.

\section{$1920-1970$}

Ya a finales del siglo XIX se inició una reacción contra la grave situación de la vivienda. Particulares, y aquellas industrias que deseaban proporcionar a sus obreros una vivienda decente, realizaron algunos esfuerzos. Como reacción contra la especulación en la construcción de viviendas, se constituyeron asociaciones de propietarios-arrendatarios que construyeron casas en las que sus miembros podian ser copropietarios de sus apartamentos. La asociación nacional de arrendatarios (HSB) se constituyó en 1923 con una política consagrada a suministrar cuartos de baño incluso en alojamientos de la clase obrera e introdujo los vertederos de basuras.

De forma gradual, la municipalidad adquirió mayor responsabilidad en materia de viviendas. En la década de los años 20 , se iniciaron los programas de construcción de propietario-ocupante bajo los auspicios de los organismos municipales (pequeñas viviendas construidas por los propietarios) y la municipalidad comenzó a prestar su asistencia en la financiación de las viviendas. La extensión de los apartamentos se redujo deliberadamente y se construyeron pequeños apartamentos de un solo dormitorio. La idea fundamental era abandonar el frecuente sistema de casas de huéspedes y dar a cada familia su propia residencia, aunque fuera pequeña.

Se produjeron, a continuación, cambios en el estilo de la edificación y en los ideales de la planificación urbanistica. Los bloques rectangulares con

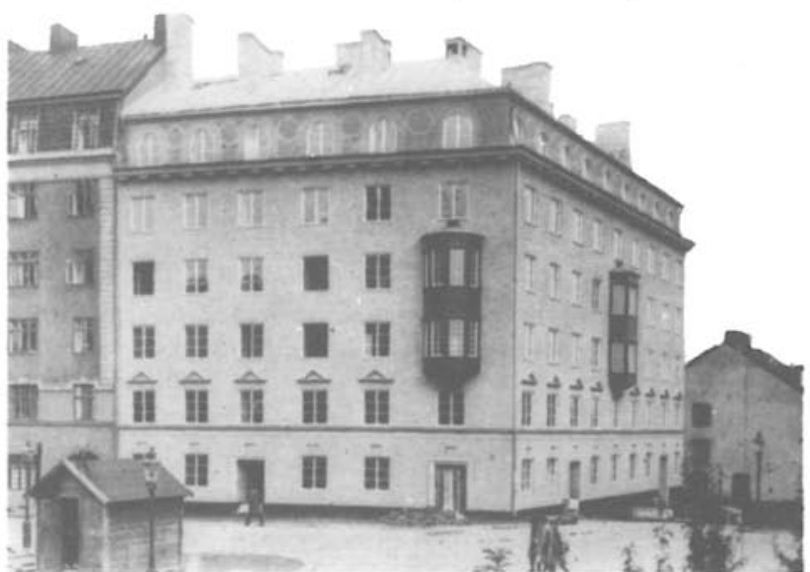




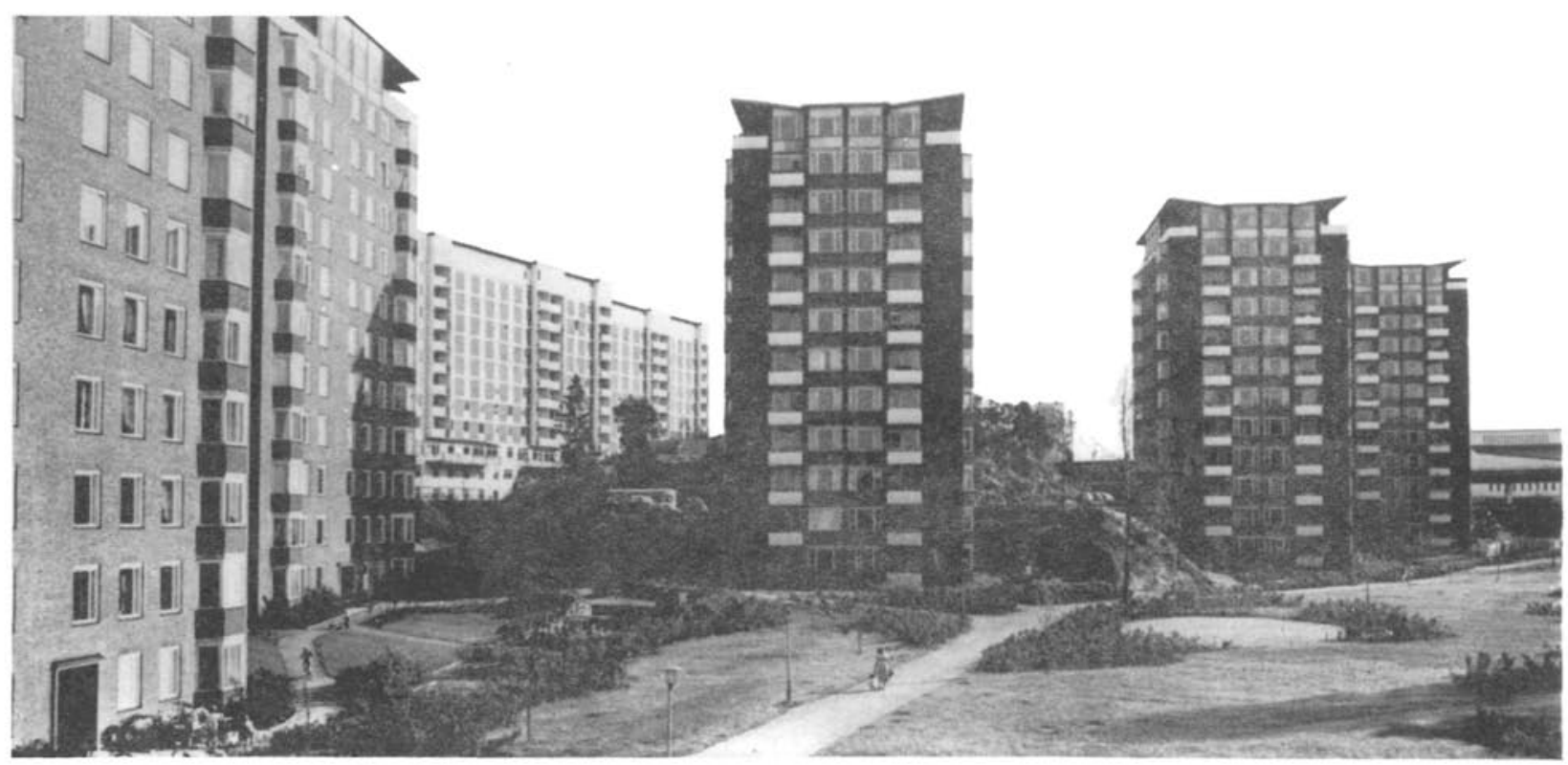

sus edificios compactos en los patios se sustituyeron por bloques más grandes y abiertos con espaciosos patios, con casas de estilo uniforme y construidas al mismo tiempo. Los mejores ejemplos de este tipo se han contemplado en la zona de Rödaberg en Vasastan, en la zona de Eriksberg en Norrmalm y en Helgalunden en Söder.

Los años 30 trajeron un nueva visión social e higiénica de la planificación urbanística. Los esfuerzos para incorporar las características de luz, aire y espacios verdes condujeron a bloques separados de apartamentos, como en la zona de Eriksdal o en Hjorthagen. Otros ejemplos pueden contemplarse en Fredhäll, Kristineberg y Norr Mälarstrand. El desarrollo de las viviendas disminuyó durante la depresión de los años 30 , para batir records a finales de la década. Además, varias casas antiguas, construidas antes de comenzar el siglo $X X$, se modernizaron durante los años 30 , y se instalaron en ellas cuartos de aseo y calefacción central.

\section{Acción de poner fin a la escasez de viviendas}

Por otra parte, se construyeron pocos apartamentos durante la Segunda Guerra Mundial. Por con-
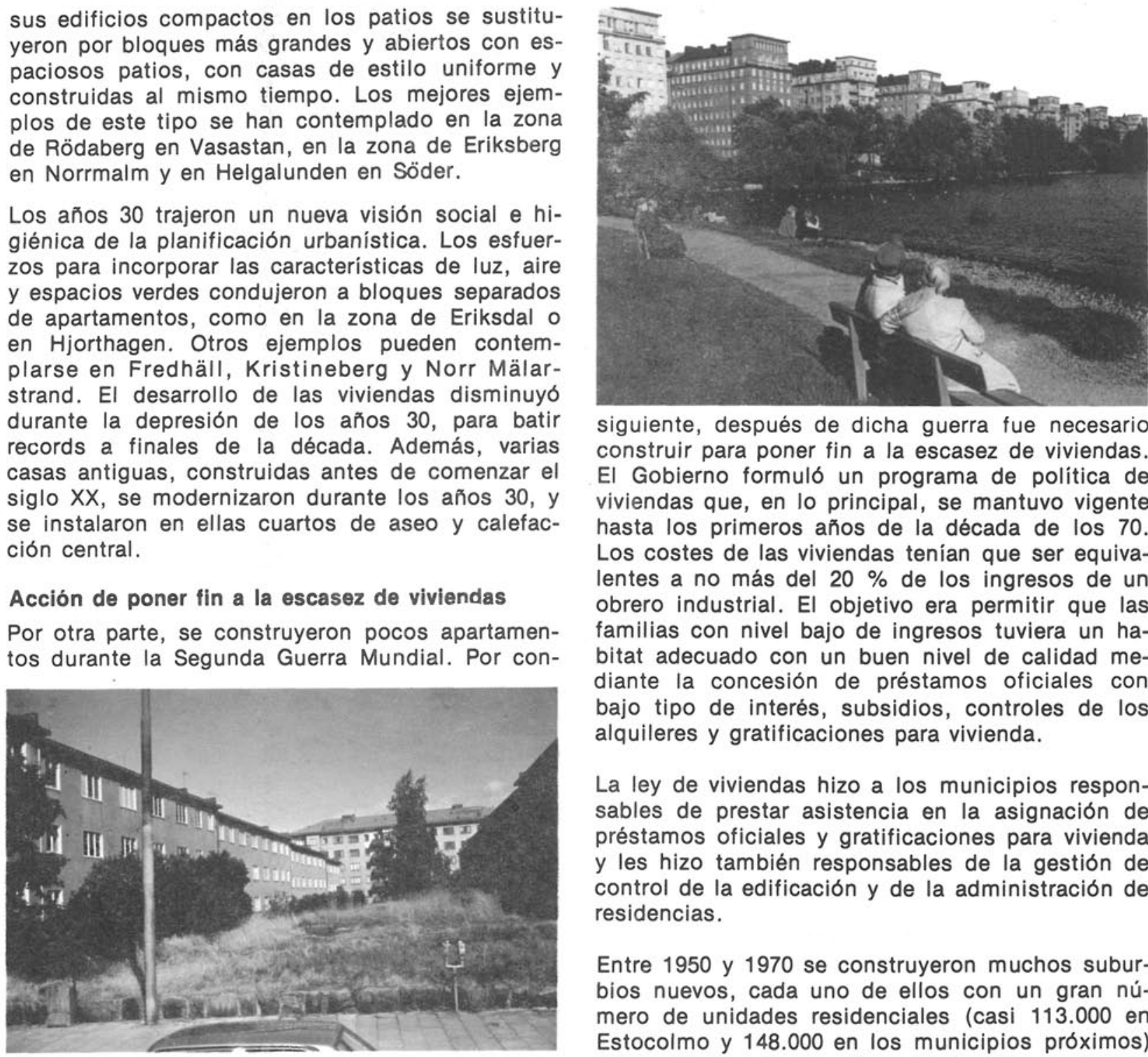

siguiente, después de dicha guerra fue necesario construir para poner fin a la escasez de viviendas. El Gobierno formuló un programa de política de viviendas que, en lo principal, se mantuvo vigente hasta los primeros años de la década de los 70 . Los costes de las viviendas tenian que ser equivalentes a no más del $20 \%$ de los ingresos de un obrero industrial. El objetivo era permitir que las familias con nivel bajo de ingresos tuviera un habitat adecuado con un buen nivel de calidad mediante la concesión de préstamos oficiales con bajo tipo de interés, subsidios, controles de los alquileres y gratificaciones para vivienda.

La ley de viviendas hizo a los municipios responsables de prestar asistencia en la asignación de préstamos oficiales y gratificaciones para vivienda y les hizo también responsables de la gestión de control de la edificación y de la administración de residencias.

Entre 1950 y 1970 se construyeron muchos suburbios nuevos, cada uno de ellos con un gran número de unidades residenciales (casi 113.000 en Estocolmo y 148.000 en los municipios próximos) 
de las que una cantidad cada vez mayor era de casas pequeñas.

Al mismo tiempo, sin embargo, se fue elevando el nivel y el deseo de tener un habitat más grande. La construcción de nuevas residencias permitió, pues, aumentar la superficie habitable en la mayor parte de las unidades residenciales, pero no alivió la escasez de viviendas hasta los años 70 . Durante este periodo de construcción de nuevas residencias, casi ningún recurso se invirtió en la renovación del habitat en las casas antiguas. Por consi. guiente, estas últimas se deterioraron en muchos casos.

\section{COMO SE VIVE EN ESTOCOLMO EN NUESTROS DIAS}

La población de Estocolmo está disminuyendo constantemente. En 1970, vivian aquí 745.000 personas, de las que 271.000 lo hacian en el centro de la ciudad. A finales de 1975 , solamente 665.000 vivian en el Municipio y de ellas 239.000 en el centro.

¿Pero cómo viven actualmente todas esas personas?

Naturalmente, el nivel de calidad de vida en lo que respecta al habitat abarca toda la gama imaginable. El peor habitat se encuentra sobre todo en las casas antiguas del centro de la ciudad. Aproximadamente 60.000 personas no tienen, por ejemplo, ni baño ni ducha o carecen de calefacción central y agua caliente. Viven en las Ilamadas viviendas sub-estándar. En 1975, unas 45.000 de las 372.000 viviendas en el Municipio eran anticua-

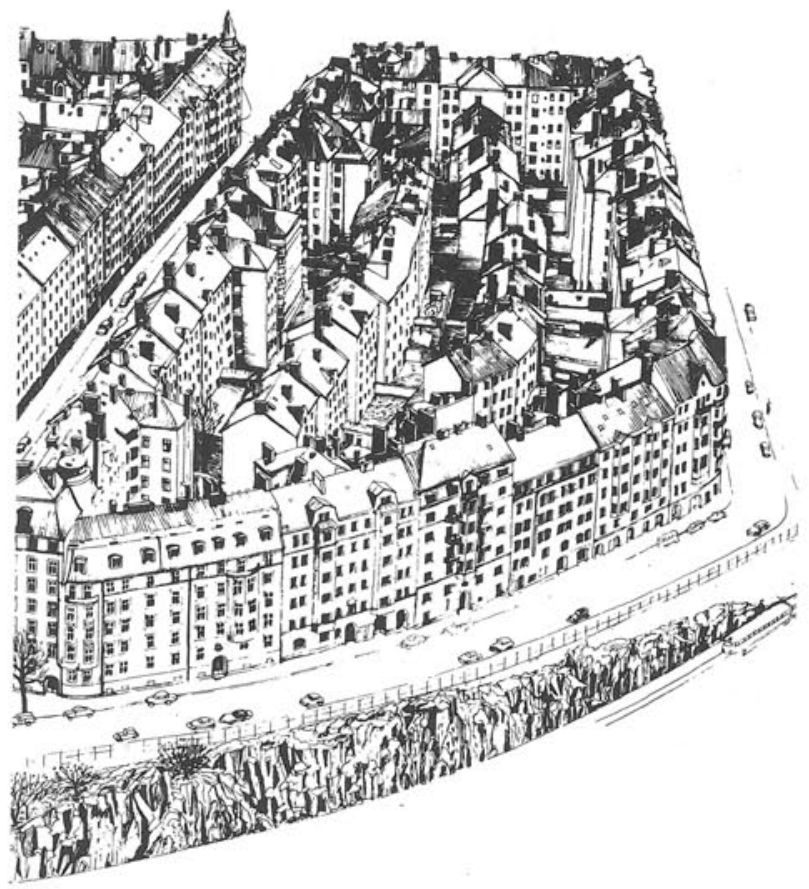

das; de ellas 35.000 estaban en el casco urbano y solamente 10.000 en los suburbios, fuera de los límites de la ciudad. Puesto que estas viviendas se construyeron por constructores privados, en su mayoría siguen siendo propiedad privada. No obstante, con fines de un nuevo desarrollo, el Municipio ha adquirido viviendas sub-estándar y ahora posee el $18 \%$ de dicho habitat.

\section{Apartamentos demasiado pequeños}

Pero el habitat puede ser malo, aunque sea moderno. Por ejemplo, el apartamento puede ser demasiado pequeño. Ello es frecuente en el casco urbano en donde más de la mitad de los apartamentos son de una sola habitación.

\section{El tamaño de los apartamentos en Estocolmo, en 1970}

$\begin{array}{ccccc}\begin{array}{c}1 \text { dormito- } \\ \text { rio y coci- } \\ \text { na o más } \\ \text { pequeño }\end{array} & \begin{array}{c}2 \text { dormi- } \\ \text { torios y } \\ \text { cocina }\end{array} & \begin{array}{c}3 \text { dormi- } \\ \text { torios y } \\ \text { cocina }\end{array} & \begin{array}{c}4 \text { dormi- } \\ \text { torios y } \\ \text { cocina o } \\ \text { más } \\ \text { grande }\end{array} \\ & 25 \% & 12 \% & 11 \%\end{array}$

(En casco urbano)
$31 \%$
$21 \%$
$28 \%$
$20 \%$

(Fuera de los limites de la ciudad)

Los efectos de las viviendas demasiado pequeñas son el hacinamiento y la segregación. En 1970 una de cada cinco familias estaba en condiciones de hacinamiento; esto es, con más de dos personas por habitación, sin contar la cocina ni la sala de estar. Una tercera parte del hacinamiento se refiere a familias con hijos de corta edad. Pero éstas son cifras para el Municipio completo y casi la mitad de las familias con niños, que viven en el casco urbano, están en hacinamiento. En este caso, el hacinamiento es especialmente grave habida cuenta de que el medio ambiente da pocas oportunidades para que los niños jueguen al aire libre.

\section{La segregación}

Quienes tienen la posibilidad de adquirir una buena vivienda no aceptan una residencia estándar o en condiciones de hacinamiento. Suelen trasladarse a un mejor habitat, normalmente en los suburbios. Algunos pueden invertir su propio dinero y trabajar para mejorar las viviendas sub-estándar. 
Los que permanecen en el peor habitat son pequeñas familias con una economia débil, junto a familias con pocas pretensiones.

Las categorias sociales de las familias varian de un lugar a otro. Determinadas categorias predominan en ciertas clases de zonas. Las residencias de las personas han llegado a segregarse exactamente en la misma forma que durante el siglo XIX, cuando los ricos y los pobres vivian separados en zonas diferentes de la ciudad o en distintas partes del mismo edificio. Pero no se trata solamente de una segregación económica. También tiene lugar una división entre familias más grandes y más pequeñas, entre la juventud y la vejez; las familias más jóvenes con hijos de corta edad abandonan el centro de la ciudad mientras que las familias compuestas por personas de mayor edad y sin niños permanecen en el casco urbano. Un $30 \%$ de quienes viven dentro de los limites de la ciudad tienen más de 65 años, mientras que en el Municipio, en su conjunto, constituyen solamente el $20 \%$.

\section{POLITICA DE VIVIENDAS EN LA DECADA DE 1970}

"A toda la población se le deberá proveer de un habitat saludable, espacioso, bien planeado y funcionalmente equipado, de buena calidad y a un coste moderadon.

Proyecto de ley 1967:100 con respecto a la politica de viviendas.

\section{Modernización en lugar de nueva construcción}

Actualmente, se ha eliminado, en su mayor parte, la escasez de viviendas, y ahora los recursos pueden concentrarse en modernizar las casas con nivel de calidad inferior al estándar.

Los controles de los alquileres se van suprimiendo paulatinamente. Durante el periodo de eliminación, los aumentos de los alquileres se deberán determinar mediante negociaciones entre la asociación de inquilinos y los propietarios de las casas. Los precios de coste de las sociedades de construcción públicas constituirán, en el futuro, la base para los alquileres de las viviendas, incluso de propiedad privada.

Los arrendatarios tienen, ahora, el derecho a pintar y a empapelar sus viviendas sin el permiso del dueño. Asimismo, tienen derechos estatutarios de intercambio y ocupación. Una mayor responsabilidad para la conservación de las viviendas incumbe ahora al dueño.

Los cambios en la politica del terreno han proporcionado a los municipios una mayor influencia sobre la construcción de las viviendas.

\section{Pautas a seguir y los objetivos}

En otoño de 1974, el Riksdag, el Parlamento sueco, aprobó una ley relativa a la renovación de la propiedad residencial, lo que significo que un propietario pueda ser obligado a renovar su propiedad a un nivel de calidad minimo aceptable que, entre otras cosas, comprende:

- calefacción central,

- baño o ducha,

- una cocina adecuadamente equipada.

Los municipios son responsables de asegurar que se ejecute en la práctica la ley sobre la renovación de la propiedad residencial, en el sentido de que todos los ciudadanos tengan acceso a una residencia de buena calidad, en un buen ambiente, a un coste moderado.

Esto se considera que es evidente en la construcción de nuevas zonas residenciales $y$, ni que decir tiene, que debe aplicarse también a la renovación de las partes más antiguas de la ciudad. Por consiguiente, el Consejo Municipal adoptó objetivos para renovación residencial en Estocolmo en el otoño de 1974.

Una buena residencia debe tener un nivel de calidad aceptable, que incluye:

- calefacción central,

- baño o ducha,

- una cocina adecuada,

- ascensor, siempre que sea posible, en viviendas de varios pisos.

Un buen ambiente debe ser tranquilo, sin riesgos de tráfico y ha de tener:

- patios con césped y plantas, más instalaciones de juegos,

- parques y otras zonas verdes no alejadas,

- un buen ambiente de tráfico con caminos de seguridad para peatones y pistas o carriles para bicicletas.

Un coste moderado del habitat, para todos, lo que significa que grandes sectores de la población reciban gratificaciones para la vivienda. Pero incluso los préstamos oficiales, con intereses bajos, influyen sobre el coste del habitat. 
Una población mezclada exige una gama amplia de tamaños de los apartamentos. Muchos de los apartamentos pequeños, dentro de los limites de la ciudad, han de agruparse para constituir viviendas más grandes adecuadas a familias con niños.

\section{Medios}

Se han determinado las pautas a seguir y los objetivos.

El programa de acción, que muestra cómo han de cumplirse estos objetivos, fue aprobado por el Consejo de Estado Real de Suecia en la primavera de 1975.

En primera instancia, el Municipio hace lo posible por conseguir acuerdos voluntarios con los propietarios de las viviendas. No obstante, para salvaguardar el programa de renovación urbana, el Municipio ha recurrido a algunos instrumentos de control, que se pueden clasificar como:

- instrumentos estimuladores,

- instrumentos correctores,

- instrumentos reguladores.

Los instrumentos estimuladores son principalmente económicos. Por ejemplo, a los propietarios se les puede conceder un préstamo oficial para vivienda con tipos de interés protegidos y garantizados (que son más bajos que los tipos de interés bancario normales), a condición de que el municipio pueda actuar como agente para todas las residencias, que los costes de modificación sean moderados, y las autoridades municipales aprueben todos los detalles del proyecto.

Además, hay préstamos de mejora ambiental y préstamos suplementarios para edificaciones culturales. El organismo municipal puede dar incluso a los propietarios una ayuda para la evacuación cuando los residentes hayan de desplazarse del edificio.

Con los instrumentos correctores, el organismo municipal puede acelerar la renovación del habitat. De acuerdo con la ley antes citada relativa a la renovación del habitat, las autoridades municipales, o la asociación de inquilinos, puede solicitar a la junta de control de alquileres que dé instrucciones al propietario para renovar su propledad y alcanzar el nivel de calidad mínimo aceptable. Sin embargo, esta ley se aplica solamente a las viviendas alquiladas. La ley sobre instalaciones puede utilizarse para asegurar la instalación de servicios comunes; por ejemplo, en el caso de gratificación para patios espaciosos. La ley de expropiaciones y la ley relativa a la opción de com- pra pueden aplicarse cuando el Municipio desea adquirir la vivienda.

Los instrumentos reguladores (la Ley de Edificación. los Estatutos de la Construcción y el Código Sueco para la Construcción) se aplican primero después de la decisión sobre la nueva construcción o la modificación y se utilizan, sobre todo, para conseguir que las renovaciones proporcionen unas viviendas adecuadas para quienes está previsto que vivan en ellas.

\section{LA INFLUENCIA DE LOS OCUPANTES}

La legislación se ha modificado actualmente para dar a los ocupantes de las viviendas, por arrendamiento, una posición más fuerte que antes. De diversas formas, el propietario de la vivienda puede ser obligado ahora a renovar un patio o propiedad en estado deficiente y también resulta posible impedir a un propietario renovar a un nivel de calidad más alto que el mínimo aceptable. En ambos casos, el ocupante puede plantear sus demandas a través de la asociación de arrendatarios.

Además, el Municipio ha intentado fortalecer la influencia de los ocupantes de las viviendas de diversas formas y ha comprobado los efectos a través de entrevistas y de consultas.

Las entrevistas. En Mariaberget, Aspudden y Birkastan, se realizaron entrevistas con una selección estadistica de los habitantes. Estos últimos emitieron sus opiniones sobre el proyecto de renovación urbana y su alcance. Durante las entrevistas, indicaron si podrian llegar a pagar un alquiler más alto y declararon si deseaban volver a ocupar sus antiguas viviendas después de la renovación.

Consultas. El Municipio ha invitado, sobre todo a los miembros de asociaciones y organizaciones pertinentes, como parte interesada, a realizar consultas. Hasta ahora, las consultas más amplias se relacionan con la propuesta de reorganización del tráfico en la totalidad del Municipio. Estas consultas se organizaron por distritos y se realizaron con gran interés.

En Birkastan, los residentes, los propietarios de establecimientos comerciales y los propietarios de viviendas tomaron parte en reuniones consultivas en el plan del área para el distrito correspondiente, que ha de constituir la base para una posterior planificación más detallada en la zona.

Las consultas sobre planificación en el plan del área para Birkastan abarcaban varios problemas: patios, y casas a través de los patios, tráfico, aparcamiento, etc. Sin embargo, los residentes estaban más interesados por discutir los alquileres después de la renovación urbana, la posibilidad de volver a las antiguas viviendas y la inten- 


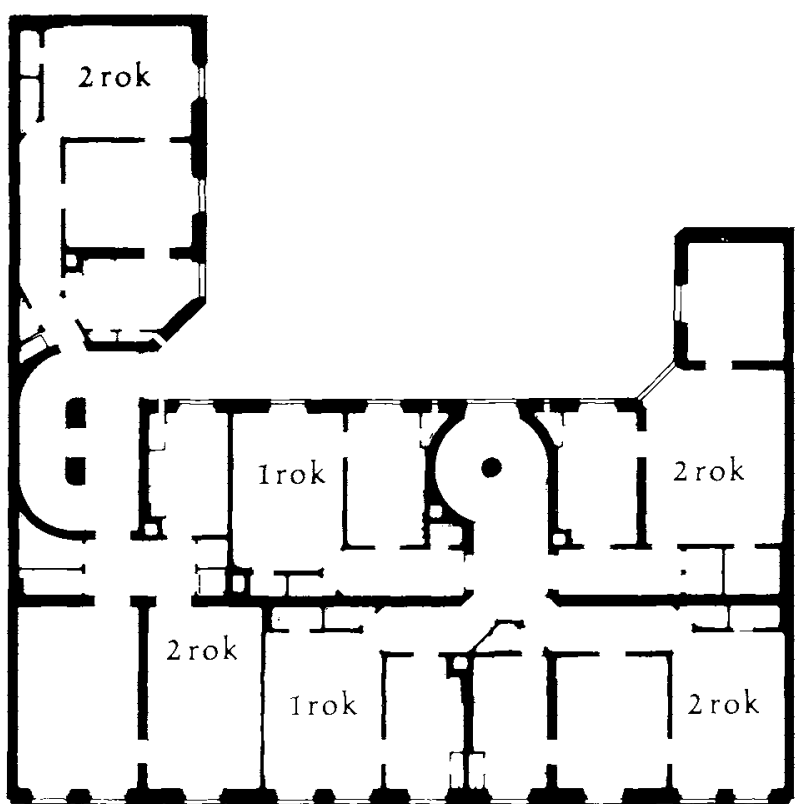

Distribución en planta con 6 pequeños apartamentos, antes de la reconstrucción.

ción del Municipio de reunir muchos apartamentos pequeños para formar otros más grandes. Sin embargo, dichas cuestiones no debian plantearse en las consultas de planificación, sino en las consultas de renovación urbana, que abarcan la renovación de los edificios y abordan los temas más importantes e inmediatos para muchas personas.

\section{NIVEL DE CALIDAD Y TAMAÑO DEL APARTAMENTO}

¿Es realmente necesario renovar las casas antiguas al nivel de calidad mínimo aceptable, que es, en cualquier caso, un nivel más bien alto?

El Parlamento sueco, Riksdag, ha promulgado leyes sobre el nivel de calidad mínimo aceptable y en consecuencia, el Municipio y el propietario individual han de renovar las viviendas para conseguir un nivel de calidad estándar, como minimo. Una de las razones en que se basa la decisión del Riksdag es que las casas han de ser adecuadas no solamente para el momento presente, sino también posiblemente para dentro de cuarenta años. Las modificaciones deben ser de un nivel admisible para quienes vivan aquí dentro de 10,20 ó 30 años. Aquellos que viven en un alojamiento por debajo del nivel estándar quizás estén acostumbrados a un nivel de calidad simple, pero es improbable que los arrendatarios futuros queden satisfechos con un nivel de calidad bajo.

Asimismo, los apartamentos renovados deben adaptarse a las exigencias de distintas clases de familia. El gran número de pequeños apartamentos que, ahora, dominan completamente en el casco urbano está previsto que se fusionen para

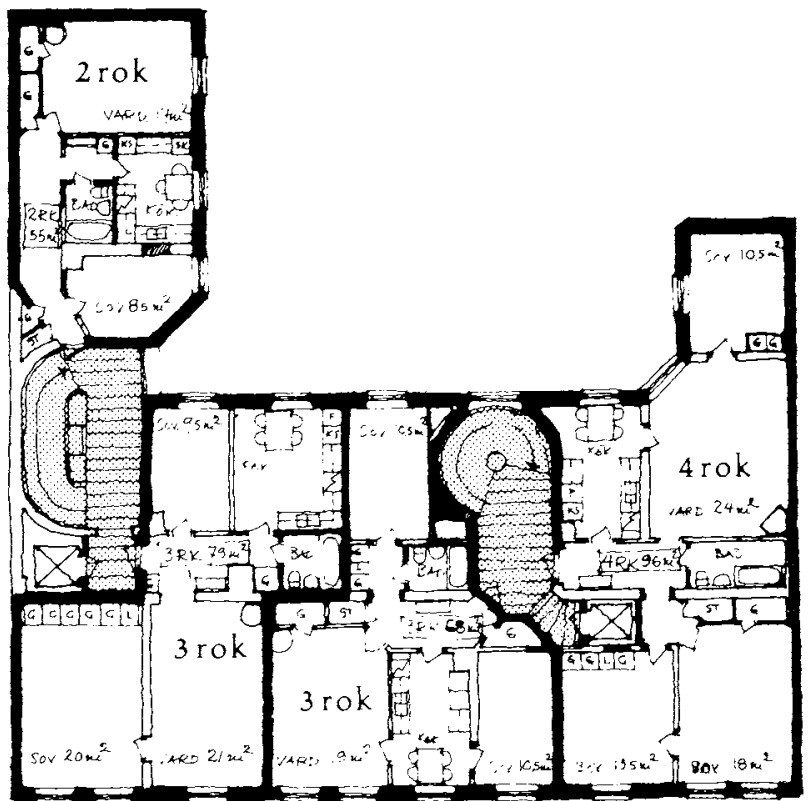

Cuatro apartamentos después de la reconstrucción.

constituir viviendas más grandes que den a las familias con niños la oportunidad de vivir en el centro de la ciudad en habitats de un buen nivel de calidad. Probablemente quienes vivan solos no estarán, en el futuro, satisfechos con un pequeño apartamento de una sola habitación, sino que preferirán un alojamiento con más espacio.

Por consiguiente, el Municipio desea que la mitad de los apartamentos, en las casas nuevas, tengan tres habitaciones y una cocina, un $25 \%$ han de ser más grandes y un $25 \%$ más pequeños. Puede ser dificil seguir estrictamente estas normas, cuando se modifiquen las casas antiguas. El diseño de la casa, junto con otros factores, deben determinar la extensión en que los apartamentos pueden fusionarse.

Con ef fin de estimular las modificaciones profundas que proporcionarán un buen nivel de calidad, el Gobierno sueco concede préstamos a largo plazo. Dichas alteraciones, con un préstamo oficial, pueden, en algunos casos, dar lugar a alquileres más bajos que sería una renovación limitada y más barata, y que debe financiarse con un préstamo a corto plazo. Por consiguiente, la concesión de un préstamo oficial exige, por regla general, un nivel de calidad más alto de renovación que el mínimo aceptable. Si los arrendatarios indicaran, a través de su asociación, que no desean un nivel más alto que el minimo aceptable, el préstamo oficial se concedería también para dicho nivel.

\section{ALQUILERES}

Durante el año 1976 se podían calcular unos alquileres medios en el margen de 8.000 a 9.500 pesetas por metro cuadrado y año, incluyendo los 


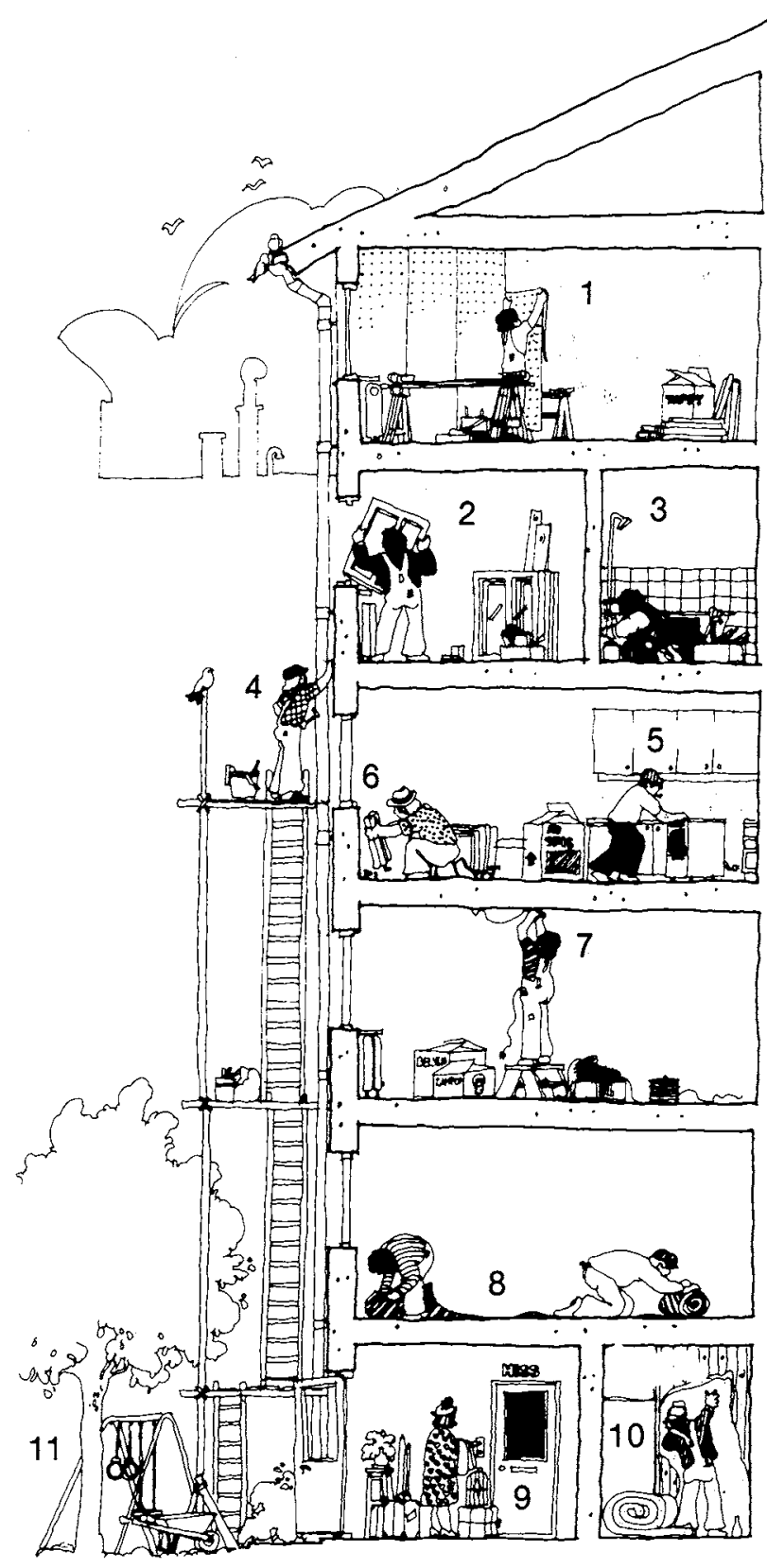

1.-Pintura y empapelado $9 \%$. 2.-Nuevas ventanas y puertas $6 \%$. 3.-WC y ducha $12 \%$. 4.-Pintura y enyesado de exteriores y escaleras $10 \%$. 5.-Cocina nueva 10\%. 6.-Radiadores nuevos $7 \%$. 7.-Instalaciones eléctricas $6 \%$. 8. - Suelos nuevos $5 \%$. 9.-Ascensor $5 \%$ 10.-Aislamiento mejorado 4\%. 11.-Instalaciones de juegos niños $4 \%$

gastos de calefacción, siempre que el nivel de calidad fuera tan alto como el de un edificio nuevo. Ello significa que un apartamento de una sola habitación y cocina, de $45 \mathrm{~m}^{2}$ costaba de 30.000 a 36.000 ptas. al mes; de dos dormitorios y cocina de $60 \mathrm{~m}^{2}$, de 40.000 a 48.000 ptas. al mes $y$ de tres habitaciones y cocina, de $75 \mathrm{~m}^{2}$, de 50.000 a 60.000 ptas. al mes. En ocasiones, se concede permiso a un propietario para demoler una casa y construir una nueva. Los alquileres en estas casas nuevas varian actualmente entre 9.000 y 10.000 pesetas por $\mathrm{m}^{2}$ y por año. Estos alquileres parecen ser altos, pero proporcionan un habitat mucho mejor que el antiguo de nivel inferior al estándar y apartamentos más baratos, que quizás no fueran tan baratos para vivir en ellos, después de todo. Con frecuencia, los gastos para el combustible, lavado de ropa, etc., se añadirian al valor del alquiler en una casa no moderna.

\section{Subvención para vivienda}

Cuando los alquileres se incrementan en grandes cantidades, muchas personas se hacen candidatas a la subvención para vivienda. La renovación al nivel de calidad mínimo aceptable, con nuevos alquileres más altos, significa que, en algunos casos, el inquilino no sufrirá un gran incremento en sus gastos de vivienda, debido a la subvención para vivienda. Con frecuencia, el Municipio paga la totalidad del alquiler para los pensionistas.

\section{Alquileres del valor de utilización}

Los costes de la renovación y de la modernización varian de una casa a otra. Las normas para los denominados alquileres del valor de utilización impiden que el propietario exija alquileres inadmisiblemente altos. Como su nombre indica, el alquiler de la residencia se determina de acuerdo con su nivel de calidad, diseño, situación, etc., y su valor para el usuario (esto es; el inquilino). Este alquiler del valor de utilización tiene su origen en los atquileres de las propiedades de las sociedades públicas de construcción y funciona como una forma de poner un límite superior en la determinación de los alquileres. Dicho de otro modo, los alquileres en casas de propiedad privada están adaptados a los niveles de alquiler en las viviendas propiedad de Svenska Bostäder, Familjebostäder y Stockholmshem. Los costes para estas compañías de renovación y de nueva construcción constituyen la base para las negociaciones con la asociación de arrendatarios sobre los alquileres en las casas de estas compañias.

El coste real de la renovación para el propietario privado no se tiene en cuenta, pues, para la determinación de los alquileres.

Costes de las diversas mejoras para las casas antiguas expresados en aumento del alquiler por $\mathrm{m}^{2}$ y por año.

\section{EL DERECHO AL REGRESO}

Con frecuencia, no es posible permanencer en una vivienda mientras se están realizando renovaciones completas. La experiencia que se ha tenido de permitir a los arrendatarios seguir ocupando la vivienda durante la renovación, no fue positiva en absoluto. Tienen que vivir, durante largos periodos, en condiciones ambientales pulverulentas, sucias y ruidosas y el trabajo de construcción no 
se puede realizar tan efectivamente como en un apartamento vacio. Si varios apartamentos pequeños se fusionan para constituir otros pocos más grandes, algunas familias tienen que desplazarse.

Por consiguiente, el propietario o el municipio ofrecen un alojamiento alternativo con la opción de ser temporal o permanente, con los derechos de posesión correspondientes. Si se eligiera una posesión temporal, el arrendatario tiene derecho a un certificado que indica que puede regresar a su vivienda anterior que ha sido objeto de renovación.

Hasta ahora, a la mayoría de los arrendatarios se les ha dado unas viviendas de tan buen nivel de calidad que no solicitaron un certificado. Ahora bien, dichos inquilinos no han aceptado el nuevo alquiler más alto en su antigua residencia. Sin embargo, ahora que la tasa de renovación urbana se ha incrementado, se ha hecho más dificil encontrar un buen alojamiento alternativo en el casco urbano y ello ha dado lugar a un aumento en el número de demandas de certificados que garanticen el derecho a volver a su antigua vivienda.

Pero el desplazarse dos veces también resulta arduo, lo que puede constituir una de las razones para que muchas personas elijan, al final, no regresar. Otro motivo puede ser la preferencia por un ambiente diferente.

\section{Menos apartamentos en casas renovadas}

Se calcula que aproximadamente 17.000 de los 45.000 apartamentos de calidad inferior a la estándar desaparecerán cuando se produzca la fusión durante la renovación urbana. De conformidad con la ley, los arrendatarios tienen derecho a volver a un apartamento del mismo tamaño en la casa renovada, siempre que sea posible. Pero el término de "siempre que sea posible" viene determinado por el número de apartamentos disponibles. Si no hay suficientes apartamentos renovados para todos, entonces, aquellos que hayan vivido más tiempo en la casa, o que tengan otros fuertes vínculos con la vecindad, tendrán prioridad para su derecho a volver.

\section{PUESTA EN PRACTICA DE LA RENOVACION DEL HABITAT RESIDENCIAL}

Hay planes de desarrollo en vigor para la totalidad del casco urbano de Estocolmo que, en su mayor parte, se elaboraron en los años 30 y 40 . Cuando se hicieron estos planes, se pensó en que las casas antiguas se demolerian $y$, por consiguiente, algunas calles se podrían ampliar fácilmente. Ahora no se piensa lo mismo. Estos planes ya no cumplen los requisitos para la conservación y renovación urbana.
En consecuencia, se está llevando a cabo un trabajo intensivo para revisar los antiguos planes $y$ elaborar otros nuevos que posibiliten la conservación de las casas antiguas. Con anticipación a la conclusión del trabajo relativo a los planes, el municipio emite ocasionalmente un bando sobre edificación en algunas vecindades.

En todo el casco urbano, un bando de demolición está actualmente en vigor. Aquellos que quieran demoler su casa antigua y construir una nueva, deben solicitar, pues, la dispensa de este bando, un permiso de demolición $y$, en ese momento, demostrar que el estado de la casa es tan malo que por ese, u otro motivo, resulta imposible la renovación.

\section{Plan zonal 70}

En los antiguos planes de desarrollo se suele indicar lo que, en determinadas vecindades, puede utilizarse para conjuntos residenciales o instalaciones comerciales. Esa es una de las razones para la, hasta ahora, construcción no sistemática de instalaciones de oficinas en el casco urbano. En el plan de utilización del terreno para el casco urbano (plan zonal 70), el consejo municipal ha decidido qué bloques se utilizarán para residencias, lugares de trabajo, centros escolares, hospitales y otras instituciones.

Sobre la base del plan zonal, se elaboraron nuevos planes de desarrollo o se añadieron reglamentaciones suplementarias a los planes antiguos.

\section{Un plan de desarrollo}

Está constituido por mapas y reglamentaciones por escrito. Regula cómo ha de dividirse el terreno en calles, plazas, parques, edificios, etc. En nuestros dias, el plan indica cómo han de utilizarse las edificaciones para residencias, lugares de trabajo, centros escolares y construcciones similares. Asimismo, indican si alguna parte de un bloque no debe construirse o si ha de dejarse espacio para conducciones o tráfico general.

Un plan de desarrollo no determina si las casas han de ser demolidas y sustituidas por edificios nuevos. El propietario debe seguir las reglamentaciones del plan de desarrollo sólo cuando quiera hacer modificaciones o construir un edificio nuevo.

También es importante saber que un plan de desarrollo solamente proporciona una estructura marco para lo que el constructor puede hacer y no para lo que debe hacer. El plan no le da el derecho a construir. Por consiguiente, el plan de desarrollo dice poco acerca de la planificación detallada de los edificios, ni sobre cuándo ha de ponerse en práctica el plan. 


\section{Nuevos planes}

El casco urbano puede dividirse en zonas en las que varía la naturaleza del plan de planificación. Algunas partes requieren unos estudios de planificación más profundos y quizás también un plan zonal total como la base de la planificación detallada que finalmente conduce a nuevos planes de desarrollo.

Muchos bloques tienen una relaciones complicadas entre edificaciones y patios de vecindad y con planes de desarrollo completamente anticuados. Son precisos estudios estadísticos exhaustivos y basándose en ellos, se proponen diversas medidas para el bloque. Dichas propuestas constituyen, entonces, la base de las denominadas instrucciones de paquete y posiblemente, para alteraciones a los planes de desarrollo.

En otras zonas, los problemas no son tan grandes y los planes de desarrollo existentes pueden utilizarse para alteraciones y nuevas edificaciones, en cuyo caso se puede ir directamente a las instrucciones "paquete" y proponer medidas de renovación urbana.

\section{Instrucciones "paquete»}

Para poder realizar modificaciones estructurales 0 para levantar edificios nuevos, los planes deben ser completos. Por consiguiente, un propietario que quiera renovar su vivienda recibirá lo que se denomina un paquete de instrucciones, elaborado por varios departamentos municipales implicados en el trabajo de la renovación urbana y que proporciona recomendaciones sobre cómo ha de realizarse la renovación. Se toman en consideración los intereses históricos y culturales, las condiciones de la planificación, el estado de las cimentaciones, etc. Si el estado de las cimentaciones fuera demasiado malo (por ejemplo, estructuras de madera podridas), la casa deberá demolerse.

\section{Plan de tlempos}

En los últimos cinco años, el número de residencias con nivel de calidad inferior al estándar en el casco urbano ha disminuido en unas 13.500. El objetivo del Municipio es renovar todas estas viviendas en un plazo de 8 a 9 años, lo que significa una media de 5.000 viviendas al año.

El Municipio realizará los programas de renovación para las viviendas que se consideren con necesidad de renovación. La propiedad moderna, en estas zonas, también resulta afectada si el patio de vecindad necesitara una reforma. Además, el Municipio está invirtiendo en la construcción de nuevas viviendas edificadas sobre terreno que, hasta ahora, se ha utilizado para otros fines; por ejemplo, viejas instalaciones industriales.
Transcurre bastante tiempo desde las primera discusiones en relación con las instrucciones de upaquete" hasta que se lleva a cabo la renovación de la propledad. Lleva tiempo la elaboración de planos, la evacuación de los inquilinos, la recepción del permiso de construcción, la solicitud de un préstamo oficial, la contratación de los obreros y la terminación de la construcción. Suelen transcurrir de dos o tres años desde el comienzo a la terminación.

\section{Consultas}

Una vez terminadas las instrucciones de paquete para un bloque, el organismo oficial competente convoca a los propietarios interesados a una reunión de contacto introductoria, a la que se invita también a la asociación de arrendatarios. Los planes municipales para el bloque son objeto de presentación junto con la información sobre cómo puede servir de ayuda el asesoramiento municipal.

Se conviene un tiempo para la inspección del habitat con el propietario correspondiente. Dicha inspección se realiza para constatar si satisfacen el nivel de calidad mínimo aceptable. Si no fuera así, se le da al propietario la tarea de planificar las renovaciones oportunas.

El propietario convocará, a su vez, a todos los ocupantes de las viviendas a una reunión informativa sobre estos planes. Cuando éstos están preparados, y tras discusión con la asociación de arrendatarios, el Municipio firma un acuerdo con el propietario. Los planes deben tener la aprobación certificada de la asociación de arrendatarios antes de que se conceda el permiso de construcción y un préstamo oficial para el proyecto correspondiente. Por consiguiente, la asociación de arrendatarios habrá tenido discusiones previas con los ocupantes. Si el propletario rehusara hacer nada para renovar la propiedad, puede verse obligado a hacerlo tal como se describe anteriormente.

\section{DESARROLLO DEL AMBIENTE URBANO}

El vivir en un buen entorno no es simplemente una cuestión de residir en una buena vivienda, en un habitat bien conservado. También es importante el nivel de calidad del ambiente circundante, que no debe estar perturbado por los humos y por el ruido del tráfico y ha de tener acceso a parques, etc., que sean seguros para pasear y para jugar.

Esto es importante para todos los grupos de edades, pero sobre todo para los nifios y para las personas de edad avanzada. Por consiguiente, debe mejorarse el patio de vecindad y el ambiente de las calles en el casco urbano para conseguir una población mezclada que es uno de las objetivos del redesarrollo urbano. 


\section{Mejoras municipales para patios de vecindad detrás de los edificios}

Para hacer que los patios de vecindad sean utilizables como zonas de exteriores y campos de juegos para los ocupantes, algo debe hacerse en relación con el ambiente del patio en conjunción con las obras de renovación, si no fuera posible con anterioridad. Una vez que hayan resuelto los problemas de recogida de basuras, batido de alfombras, etc., los propietarios pueden agruparse y crear un solo patio común espacioso. El Municipio puede influir en los propietarios hacia dicha colaboración.

En muchos casos, es necesario demoler las casas que dan sombras excesivas, construidas mirando al patio de vecindad. Otra forma de hacer dicho patio más accesible es abrir entradas a través de las casas entre los patios. Pueden plantearse problemas por las grandes diferencias de nivel entre un patio y otro, y las paredes, vallas y elementos similares deben retirarse o destruirse.

Para hacer un patio agradable y utilizable por todos los grupos de edades, deben procurarse ajardinamiento e instalaciones de juegos, etc. Los patios denominados de construcción insuficiente pueden causar problemas pero, a veces, tienen árboles y otras plantas para constituir la base de una zona verde para los ocupantes de las viviendas circundantes.

\section{Reorganización del tráfico}

El "Trafikplan 75 ", el plan municipal para el tráfico en Estocolmo, incluye una propuesta para la reorganización del tráfico, que desviará, en la medida de lo posible, el tráfico de las calles residenciales.

La propuesta cubre a todo el Municipio y proporcionará al casco urbano un sistema de tráfico similar al probado, durante varios años, en Ostermalm y en el distrito de Katarina en Söder. La propuesta establece que ha de ser posible llegar a todos los edificios en automóvil, pero transformando muchas calles en "callejones sin salida", se utilizarán solamente por el tráfico que realmente tenga algo concreto que hacer en ese lugar. Todo el resto del tráfico se dirige a caminos con preferencias de paso más grandes, denominados carreteras colectoras. Sin embargo, estas restricciones se aplican solamente a los automóviles. Se puede pasear en bicicleta y a pie como antes $y$ quizás incluso con más facilidad y seguridad.

La reorganización del tráfico puede proporcionar a algunas personas un ambiente de tráfico más desfavorable por el aumento del tráfico en su habitat. Pero la mayoria vivirá en calles más tranquilas y menos ruidosas.

\section{MEJOR SERVICIO}

De forma simultánea con la renovación del habitat, el Municipio está invirtiendo en la mejora de los servicios sociales para los ocupantes. Nuevas guarderias han de construirse dentro y fuera de los límites de la ciudad y están planificadas más residencias para pensionistas.

El Consejo del Condado está trabajando también para acercar el servicio sanitario a la población y está prevista la construcción de varios centros para pacientes externos, con servicios médicos $y$ de odontologia, etc.

En el conjunto de Riddarsporren, cerca de Odenplan, se puede estudiar una propuesta sobre cómo combinar las zonas residenciales con las guarderías y los servicios para las personas de edad avanzada. En este lugar estaba situada la antigua cervecería Hamburger que actualmente se ha demolido, en parte, logrando espacio para nuevos conjuntos residenciales, guarderías y residencias para pensionistas. Las antiguas viviendas de la zona están siendo objeto de renovación y una parte de las instalaciones de la cerveceria se ha conservado y utilizado como centro médico y para otras actividades de quienes viven en el conjunto residencial o en sus proximidades.

Los centros escolares en el casco urbano están amenazados con el cierre. Las escuelas deben mantenerse abiertas si se ha de evitar, por ei tráfico al centro escolar, que los niños hagan largos, molestos, y peligrosos los desplazamientos. Para poder mantener la actividad de las escuelas, un número suficiente de alumnos debe vivir en cada distrito escolar. Por consiguiente, es importante que los conjuntos residenciales en el casco urbano estén ocupados por una población mixta y que incluso familias con niños se desplacen a esta zona.

También es importante vivir cerca de las tiendas, estafetas de correos y establecimientos similares, tal como ocurre actualmente. Dichos servicios siguen siendo abundantes en el casco urbano. Sin embargo, si han de sobrevivir los establecimientos comerciales, la clientela no debe disminuir todavia más.

\section{COMPETENCIAS}

\section{EL PROPIETARIO DEL HABITAT}

Tanto si se trata de propiedad privada como municipal, el propietario es responsable de asegurar que tenga buenas condiciones higiénicas como vivienda. Como se dijo anteriormente, el propietario puede verse obligado a modernizar sus viviendas si no tomara la iniciativa por si mismo. 


\section{EL MUNICIPIO}

La Junta Urbanizadora (constituida por políticos), a través del Departamento de Urbanismo (funcionarios municipales), tiene la responsabilidad principal para la renovación de conjuntos residenciales en Estocolmo. Pero muchas otras juntas y departamentos municipales tienen responsabilidad con respecto a diversas partes del proceso de renovación de las zonas residenciales.

\section{El Comité de Edificación/El Departamento de Planificación y Control}

Establece planes de urbanismo que regulan la utilización de los emplazamientos de bloques.

Es responsable de la consulta con los ocupantes y otras partes afectadas por los planes de distrito $y$ de conjuntos residenciales.

Concede permisos de construcción para nueva edificación, reconstrucción y las ampliaciones y adiclones.

Inspecciona la propiedad residencial y los patios de vecindad como una base para el trabajo del Municipio en la iniciación del redesarrollo.

Es responsable del establecimiento legal de los lindes.

Inicia el establecimiento de instalaciones comunes; esto es, la unión de patios de vecindad, garajes en comunidad, etc.

Mantiene una vigilancia somera de la relación entre la renovación del conjunto residencial y la función más general del distrito, junto con las planificaciones del servicio, del tráfico, de los distritos comerciales, etc.

Establece las pautas a seguir para planificar niveles de calidad, v.g. el redesarrollo de patios de vecindad.

\section{El Comité de Urbanismo/la Oficina de Urbanismo}

Elabora planes quinquenales para la renovación de los conjuntos residenciales.

Es la agencia municipal para las solicitudes de préstamos oficiales para viviendas.

Inicia la renovación de las viviendas que estén por debajo del nivel de calidad minimo aceptable y comprueba que se están realizando las renovaciones.
Inicia la consulta entre los propietarios y los inquilinos.

Presta su asistencia a la evacuación de los arrendatarios.

Asesora y dirige, junto con otros departamentos municipales, la renovación de edificios individuales, mediante un paquete de instrucciones.

\section{La Junta de Asuntos Culturales/EI Museo de la Ciudad}

Realiza las evaluaciones culturales e históricas como una base para las decisiones tomadas por el Comité de Edificación sobre la demolición o proyectos de nuevas construcciones.

Asegura que los valores culturales e históricos se conserven en la obra de renovación.

Examina la posibilidad de préstamos suplementarios para centros culturales.

Asesora y dirige en las cuestiones de valores antiguos.

El Comité del Medio Ambiente y Sanidad Pública/EI Departamento de Sanidad Pública

Toma medidas cuando las condiciones sanitarias en las viviendas se hacen demasiado deficientes.

\section{La Junta Central de Bienestar Social/EI Departamento de Bienestar Social}

Presta su asistencia en la mitigación de problemas de ajuste social que se deriven de la renovación de conjuntos residenciales.

\section{El Departamento de Urbanismo de Estocolmo y su} Junta (oficinas de urbanismo local)

Ayuda a la evacuación de los arrendatarios.

Dirige a los arrendatarios a las viviendas recientemente renovadas y construidas.

\section{ASOCIACION DE ARRENDATARIOS}

Además de los departamentos municipales, la asociación de arrendatarios está implicada en el redesarrollo participando en reuniones de información y de consulta que aprueben proyectos en los que el nivel de calidad sea superior al minimo aceptable. 